\title{
Parametric analysis of ply properties on composite cylinder design for spacecrafts
}

\author{
VIJAYAKUMAR SAHADEVAN ${ }^{\mathrm{a}}$ \\ Laboratoire d'Ingénierie des Systèmes Mécaniques et des Matériaux, Institut Supérieur de Mécanique de Paris, \\ 3 rue Fernand Hainaut, 93407 Saint Ouen Cedex 01, France
}

Received 28 March 2003, Accepted 8 July 2005

\begin{abstract}
This paper presents the parametric analysis of ply properties on composite cylinder design for satellites. The composite cylinder is modelled as a sandwich construction type with honeycomb as a core and a multi-layer laminate composed of CFRP (Carbon Fiber Reinforced Plastics) plies as a skin. A design algorithm is developed with the help of $\mathrm{C}$ programs interfaced with IDEAS EDS for finite element analysis. During simulation, the different subsystems and panels are idealised as a mass load applied at their centre of gravities. Different parameters such as aspect ratio, ply orientation and number of plies have been analysed for arriving optimum design satisfying the static and frequency constraints. This approach is well implemented in the design and development of composite cylinder for different satellites and their validation with tests are under development.
\end{abstract}

Key words: Finite elements / satellites / structural analysis / composites / IDEAS

Résumé - Analyse paramétrique des propriétés de couche sur la conception d'un cylindre composite pour satellites. Cet article porte sur la conception de cylindre composite pour satellites avec une approche d'analyse paramétrique. Le cylindre composite est modélisé par une couche de nid d'abeille dans le cœur et un laminé multicouche de CFRP (Carbon Fiber Reinforced Plastics) pour la peau. Un algorithme pour la conception est développé à l'aide d'un programme en $\mathrm{C}$ et d'une interface avec IDEAS EDS pour l'analyse éléments finis. Au cours de la simulation, les différents sous-systèmes et panneaux sont modélisés par une charge aux centres de gravité respectifs. Différents paramètres comme la géométrie, l'angle et le nombre de couches sont étudiés pour obtenir la valeur optimum qui satisfait les contraintes fréquentielles et statiques. Cette approche est bien implémentée pour la conception et le développement du cylindre composite pour différents satellites et en cours de validation pour les expérimentations.

Mots clés : Élément finis / satellites / calcul de structure / composites / IDEAS

\section{Introduction}

The spacecraft structural design is a complicated iterative process that involves materials selection, configuration, analysis and verification testing. Structural design is very dependent on the design requirements of other subsystems [1]. The configuration is the first and most important step in design. For a Gamma bus configuration [2], high number of constraints and high ratio of invalid designs found very common difficulty. The configuration studies must precede a detailed analysis of loads that are evolved due to various subsystems and standard payloads [3]. The small satellite development experiences rendered many researchers for understanding the

a Corresponding author: vijay.koumar@gmail.com spacecraft design. For the illustration, the ICARUS structure [4] is made of aluminium panels and does not require any complex analysis. Similarly, the MSX spacecraft design [5] performed with the help of NASTRAN also metallic ones. However, the coupling of spacecraft finite element model with launch vehicle simulation is adopted in this paper.

The central cylinder of a satellite structure forms the main load-bearing member of a spacecraft. It supports propellant tanks, various panels and other subsystems. The panels carrying payloads are mounted around the cylinder giving the spacecraft a cubical shape. The base of the cylinder mates with the launch vehicle adapter through an interface ring with specially designed clamp band system. Many of the researches [2-5] have been contributed to metallic corrugated cylinders. There is a 


\section{Nomenclature}

\begin{tabular}{|ll|}
\hline$d$ & Mean diameter of the cylinder, m \\
$E_{L L}, E_{T T}$ & Lamina Young modulus in fiber and transverse directions, N.m ${ }^{-2}$ \\
$E_{11}, E_{22}$ & Laminate effective Young modulus in fiber and transverse directions, N.m ${ }^{-2}$ \\
$G_{L T}$ & Shear modulus of lamina in plane, N.m ${ }^{-2}$ \\
$G_{L 3}, G_{T 3}$ & Shear modulus of lamina in thickness wise planes, N.m ${ }^{-2}$ \\
$g_{x}, g_{y}$ & Axial and transverse acceleration due to gravity respectively, $\mathrm{m} . \mathrm{s}^{-2}$ \\
$h_{\mathrm{f}}, h_{\mathrm{c}}$ & Thickness of face skin and core respectively, $\mathrm{m}$ \\
$\mathrm{M}$ & Moment, Nm \\
$m_{\mathrm{s}}$ & Mass of the satellite, kg \\
$N_{x}, N_{x y}$ & Axial and inplane load per unit length, N.m ${ }^{-1}$ \\
$P$ & Axial load, N \\
$\bar{X}$ & X coordinate of center of gravity of satellite, $\mathrm{m}$ \\
{$[\sigma]$} & Design stress, N.m ${ }^{-2}$ \\
$\sigma_{x}, \sigma_{x y}$ & Axial and inplane stresses, N.m \\
$\sigma_{\mathrm{w}}, \sigma_{\mathrm{d}}, \sigma_{\mathrm{c}}$ & Stresses due to wrinkling, dimpling and shear crimping respectively, N.m \\
$\varsigma_{\mathrm{w}}, \varsigma_{\mathrm{d}}, \varsigma_{\mathrm{c}}$ & Factor of safety against wrinkling, dimpling and shear crimping \\
$\nu_{L T}$ & In plane Poisson ratio of lamina \\
$\nu_{12}$ & In plane effective Poisson ration of laminate \\
$\psi$ & Load factor \\
$\rho$ & Density, kg.mm \\
\hline
\end{tabular}

little development on fully composite version of spacecraft primary structures. The design of composite cylinder is difficult due to anisotropy nature, fabrication and joint complexities. Sodel [6] might be the first researcher who formulated analytical solutions for vibration characteristics of such composite shells made of orthotropic laminates. Sharma [7] also extended the same for fluidfilled cylindrical shells. However, due to weight, strength and reliability constraints the sandwich construction has been preferred for space applications. For sandwich construction, low density cores and high strength face skins are important [8]. The fundamental problem with sandwich structures are their failure due to local phenomena such as dimpling and wrinkling of face skins and some times shear crimping of the core at extreme loading conditions [9]. Reese et al. [10] has developed simplified design equations for sandwich cylinder made of othrotropic facings and a soft core. These equations are extended using a ply-by-ply design concept by Vijayakumar et al. [11,12] with the inclusion of load factors and other failure safe constraints relevant to spacecraft design. The vibration levels are very critical for spacecrafts and the developed design must validate through analysis and testing [13].

The computer aided design (CAD) tools and finite element analysis (FEA) softwares are increasingly used for spacecraft design. This paper presents the parametric analysis of ply properties such as ply orientation angle, number of plies and their sequency on composite cylinder design for satellites. The composite cylinder is modelled as a sandwich construction type with honeycomb as a core and a multi-layer laminate composed of CFRP (Carbon Fiber Reinforced Plastics) plies as a skin. A design algorithm is developed with the help of $\mathrm{C}$ programs interfaced with IDEAS EDS [14] for finite element analysis. During simulation, the different subsystems and panels are idealised as a mass load applied at their centre of gravities. The next section describes the basic design equations for composite sandwich cylinder design followed by a detailed parametric analysis. The final lay-up properties are validated with finite element analysis for design and frequency constraints.

\section{Basic design equations}

The basic design equations for composite sandwich cylinder, are further derived from the works of Reese [10] and Vijayakumar [12] incorporating various load factors and modified stress calculations. Before going for CAD modeling and FEA, an analytical formulation has been derived to calculate design stress levels. At first the total load $(P)$ and bending moment $(M)$ applied on cylinder of mean diameter $(d)$ can be determined using:

$$
P=m_{\mathrm{s}} \cdot g_{x} \cdot \psi \quad M=m_{\mathrm{s}} \cdot g_{y} \cdot \psi \cdot \bar{X}
$$

where $m_{\mathrm{s}}$ is mass of the spacecraft in $\mathrm{kg}, g_{x}, g_{y}$ are the axial and transverse acceleration due to gravity respectively in $\mathrm{m} . \mathrm{s}^{-2}, \bar{X}$ is the $X$ coordinate of center of gravity of spacecraft in $\mathrm{m}$ and $\psi$ is the load factor of range $1-3$.

Using equation (1), the load per unit length in axial $\left(N_{x}\right)$ and in-plane $\left(N_{x y}\right)$ directions can be calculated using:

$$
N_{x}=\frac{P}{\pi d}+\frac{4 M}{\pi d^{2}} \quad N_{x y}=\frac{m_{\mathrm{s}} \cdot g_{y} \cdot \psi}{\pi d}
$$

The axial $\left(\sigma_{x}\right)$ and in-plane $\left(\sigma_{x y}\right)$ stresses can be derived using:

$$
\sigma_{x}=\frac{N_{x}}{2 h_{\mathrm{f}}} \quad \sigma_{x y}=\frac{N_{x y}}{2 h_{\mathrm{f}}}
$$


Table 1. Material properties.

\begin{tabular}{lcccc}
\hline Property & G837/914 & M55J/914 & HRH-10 & Aluminium \\
\hline$E_{L L}, \mathrm{M} \mathrm{Pa}$ & 100830 & 270000 & 0.01 & 74000 \\
$E_{T T}, \mathrm{M} \mathrm{Pa}$ & 100830 & 5535 & 0.01 & 74000 \\
$G_{L T}, \mathrm{M} \mathrm{Pa}$ & 4440 & 3870 & - & 26320 \\
$G_{L 3}, \mathrm{M} \mathrm{Pa}$ & - & - & 189.7 & - \\
$G_{T 3}, \mathrm{M} \mathrm{Pa}$ & - & - & 91.4 & - \\
$\nu_{L T}$ & 0.03 & 0.365 & 0.003 & 0.3 \\
$\rho .10^{-9}, \mathrm{~kg} . \mathrm{mm}^{-3}$ & 1550 & 1760 & 32 & 2700 \\
\hline
\end{tabular}

where $h_{\mathrm{f}}$ is face skin thickness in m. Using equation (3), the design stress $([\sigma])$ for sandwich construction using classical laminate theory can be arrived as:

$$
[\sigma]=\frac{2 \sigma_{x}}{4+\sqrt{\sigma_{x}^{2}+\sigma_{x y}^{2}}}
$$

By taking the above calculated values of $N_{x}$ and $N_{x y}$, laminate analysis is used to find strength margin and ply stresses. Tsai-Wu theory is used to assess the failure of the individual ply by the assumption that the design is safe if the Tsai-Wu index is less than 1. Apart from ply stresses and ply strains, the face skin dimpling, wrinkling and core shear crimping are common mode of failures in sandwich cylinders during buckling loads. Hence, the design check has to carried out for these failures. As the face skin is made of CFRP orthotrophic layers, from their equivalent modulus, the factor of safety $\left(\varsigma_{\mathrm{d}}, \varsigma_{\mathrm{w}}\right)$ against dimpling and wrinkling stresses $\left(\sigma_{\mathrm{d}}, \sigma_{\mathrm{w}}\right)$ are calculated using:

$$
\begin{gathered}
\sigma_{\mathrm{d}}=\frac{2 \sqrt{E_{11}^{\mathrm{f}} E_{22}^{\mathrm{f}}}}{1-\nu_{12}^{\mathrm{f}} \nu_{21}^{\mathrm{f}}}\left(\frac{h_{\mathrm{f}}}{d}\right)^{2} \quad \varsigma_{\mathrm{d}}=\frac{\sigma_{\mathrm{d}}}{[\sigma]}-1 \\
\sigma_{\mathrm{w}}=\frac{8}{9} \frac{E_{11}^{\mathrm{c}} \sqrt{E_{11}^{\mathrm{f}} E_{22}^{\mathrm{f}}}}{1-\nu_{12}^{\mathrm{f}} \nu_{21}^{\mathrm{f}}}\left(\frac{h_{\mathrm{f}}}{h_{\mathrm{c}}}\right)\left(\frac{2 d+h}{2 d}\right) \quad \varsigma_{\mathrm{w}}=\frac{\sigma_{\mathrm{w}}}{[\sigma]}-1
\end{gathered}
$$

where superscript and subscript f,c stands for face skin and core. $h$ denotes the thickness of the laminate. For the validation, the factor safety against wrinkling and dimpling must be greater than 1 . The honeycomb core may experience shear crimping failure at certain loads. Hence the shear crimping stress $\left(\sigma_{\mathrm{c}}\right)$ and the factor of safety $\left(\varsigma_{\mathrm{c}}\right)$ against shear crimping are derived as:

$$
\sigma_{\mathrm{c}}=\sqrt{\frac{E_{11} E_{22}}{1-\nu_{12} \nu_{21}}}\left(\frac{2 h_{\mathrm{f}}+h_{\mathrm{c}}}{d}\right) \quad \varsigma_{\mathrm{c}}=\frac{\sigma_{\mathrm{c}}}{[\sigma]}
$$

The factor of safety against shear crimping should be below 2 for the design validation. Apart from the above design constraints for static loads, the composite cylinder should also fulfill the requirement of launch vehicle frequency levels. The first resonant frequency of the cylinder must be above the excitation frequency of all other subsystems to avoid catastrophic dynamic failures.

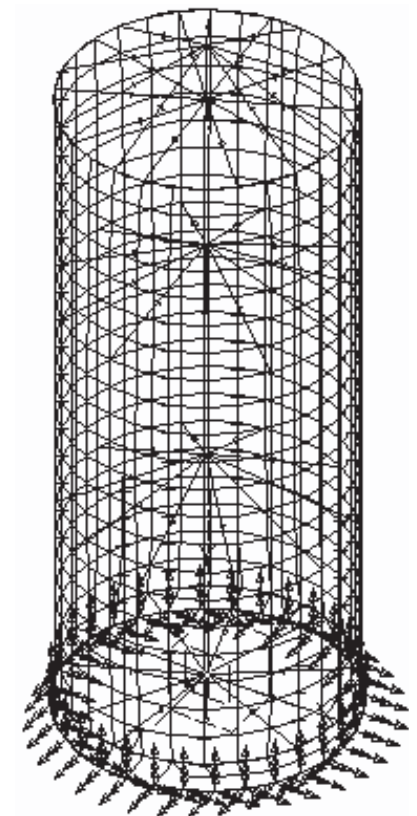

Fig. 1. FE model of composite sandwich cylinder.

\section{Parametric analysis}

\subsection{FE modelling}

The present study explains how various ply properties effect the design of CFRP honeycomb sandwich cylinder. The geometry of the cylinder is, mean diameter: $1200 \mathrm{~mm}$ and total height: $2650 \mathrm{~mm}$. It has to accommodate different payloads of a typical communication satellite. The net mass of all payloads is assumed as $3000 \mathrm{~kg}$. The cylinder is appended with an interface ring made of aluminium of height $125 \mathrm{~mm}$. For carrying out the parametric study, the CAD model of the same is modeled using IDEAS and then meshed using SHELL elements. The cylinder is segmented in to many regions to distribute different loads from its subsystems and panels. The oxygen and fuel tank loads are modeled as lumped masses at their center of gravity with the help of radially released beam elements. The loads coming through the shear webs are distributed as lumped masses along the height of the cylinder. The cylinder is constructed using CFRP prepregs and a honeycomb core. The material properties for M55J/914, G837/914 and HRH-10 are listed in Table 1. The FE model of cylinder along with idealized loads is shown in Figure 1. The 
Table 2. Basic lay-up details of composite sandwich cylinder.

\begin{tabular}{cccccccccc}
\hline Zones & \multicolumn{1}{c}{ Height $(\mathrm{mm})$} & \multicolumn{6}{c}{ Ply } & orientation (from external surface) \\
\hline Interface Ring & 0 & 28 & {$[0 / 90]$} & \pm 45 & \pm 45 & +35 & 0 & 0 & -35 \\
Ox-Tank (OT) & 28 & 485 & {$[0 / 90]$} & \pm 45 & \pm 45 & +35 & 0 & 0 & -35 \\
OT Interface & 485 & 725 & {$[0 / 90]$} & \pm 45 & \pm 45 & +35 & 0 & 0 & -35 \\
Fuel Tank (FT) & 725 & 1675 & {$[0 / 90]$} & - & - & +35 & 0 & - & -35 \\
FT Interface & 1765 & 1915 & {$[0 / 90]$} & \pm 45 & \pm 45 & +35 & 0 & - & -35 \\
Top & 1915 & 2650 & {$[0 / 90]$} & - & - & +35 & - & - & -35 \\
\hline
\end{tabular}

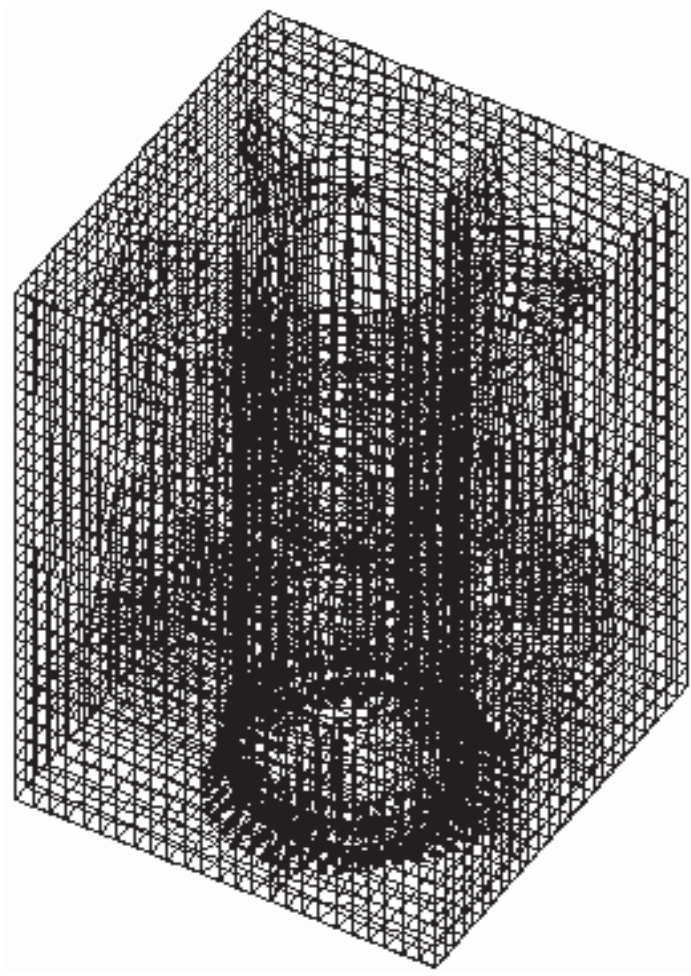

Fig. 2. Full level FE model of spacecraft.

approximate number of elements is 1800. The full level FE model where all supporting panels and shear webs are also modeled is also shown in Figure 2. The approximate number of finite elements is 12400 . The interface ring and cylinder are appended by coupling the common nodes.

The design constraints are first resonant frequency, ply stresses and strains, factor of safety against dimpling, wrinkling and shear crimping. The frequency constraint is based ARIANE $\mathrm{V}$ launch vehicle specification and is considered as above $12 \mathrm{~Hz}$. During free vibration analysis the clamped-free boundary condition is applied where as in buckling analysis fixed-free boundary condition is applied. The assumed values are $\psi=1.25, g_{x}=6 \mathrm{~g}$ and $g_{y}=1 \mathrm{~g}$.

\subsection{Effect of ply orientation angle on design}

The advantage of using composite for many space applications is its good weight to strength ratio and

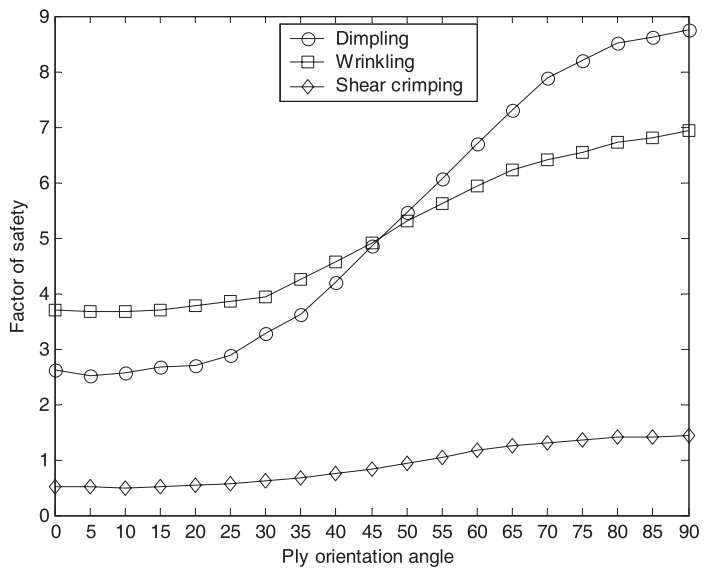

Fig. 3. Effect of ply orientation angle on design constraints $\left\{[0 / 90] / \pm 45 /+35 /(0)_{2} /-35 / H C\right\}_{\mathrm{AS}}$.

directional properties. Hence to understand how the ply orientation of prepregs in the laminate affects various behaviours.

The cylinder is segmented in to six regions as interface ring, ox tank, ox tank interface, fuel tank zone, fuel tank interface and top region. Table 2 shows the basic lay up and ply orientation of sandwich laminate face skin. The honeycomb core thickness is kept constant as $20 \mathrm{~mm}$. The ply orientation angle is varied from 5 degrees to 90 degrees. In general, zero degree unidirectional CFRP plies impart longitudinal stiffness to the cylinder whereas CFRP angle plies provide the transverse stiffness. The longitudinal stiffness increases up on increase in ply orientation up to 45 degrees and then decreases. The effects of ply orientation on factor of safety against dimpling stress, wrinkling stresses and shear crimping stresses are shown in Figure 3. The increase in factors is due to increase in the effective elastic modulus values as the ply orientation increases. The factor of safety against dimpling and wrinkling stresses are above 1.0 and also the shear crimping factor is less than 2.0 which satisfies the requirement for avoiding local buckling failure.

\subsection{Effect of ply sequence and number of plies on design}

The effective moduli and mechanical properties are varied up on number of plies and its sequence. A parametric study is done to understand the optimum number 
Table 3. Final lay-up details for composite sandwich cylinder.

\begin{tabular}{cccccccccc}
\hline \multicolumn{1}{c}{$\begin{array}{c}\text { Height of } \\
\text { CYL.(mm) }\end{array}$} \\
\hline 0 & 700 & $0 / 90$ & \pm 45 & $0 / 90$ & \pm 45 & +35 & 0 & 0 & -35 \\
700 & 720 & $0 / 90$ & \pm 45 & $0 / 90$ & - & +35 & 0 & 0 & -35 \\
720 & 740 & $0 / 90$ & \pm 45 & - & - & +35 & 0 & 0 & -35 \\
740 & 760 & $0 / 90$ & - & - & - & +35 & 0 & 0 & -35 \\
760 & 860 & - & - & - & - & +35 & 0 & 0 & -35 \\
860 & 1674 & - & - & - & - & +35 & 0 & - & -35 \\
1674 & 1694 & $0 / 90$ & - & - & - & +35 & 0 & - & -35 \\
1694 & 1714 & $0 / 90$ & \pm 45 & - & - & +35 & 0 & - & -35 \\
1714 & 1734 & $0 / 90$ & \pm 45 & $0 / 90$ & - & +35 & 0 & - & -35 \\
1734 & 1854 & $0 / 90$ & \pm 45 & $0 / 90$ & \pm 45 & +35 & 0 & - & -35 \\
1854 & 1874 & $0 / 90$ & \pm 45 & $0 / 90$ & - & +35 & 0 & - & -35 \\
1874 & 1894 & $0 / 90$ & \pm 45 & - & - & +35 & 0 & - & -35 \\
1894 & 1914 & $0 / 90$ & - & - & - & +35 & 0 & - & -35 \\
1914 & 2014 & - & - & - & - & +35 & 0 & - & -35 \\
2014 & 2650 & - & - & - & - & +35 & - & - & -35 \\
\hline
\end{tabular}

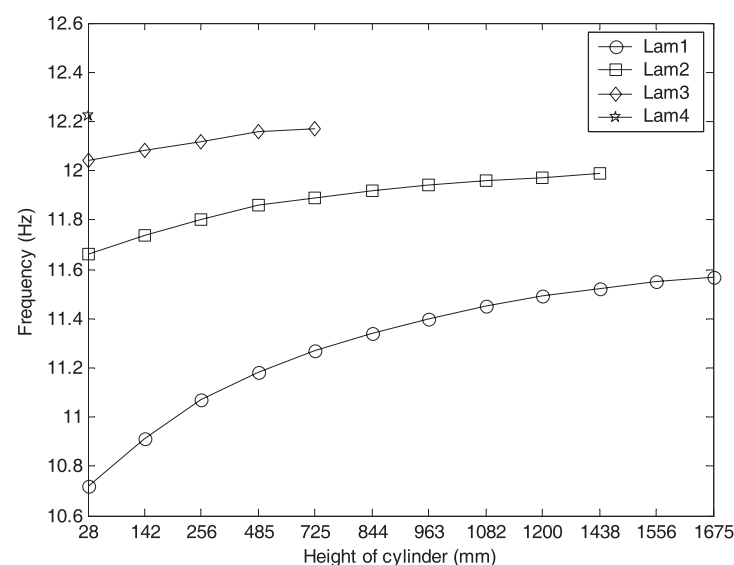

$\operatorname{Lam} 1=\{[0 / 90] /+35 / 0 /-35 / \mathrm{HC}\}_{\mathrm{AS}}$ $\operatorname{Lam} 2=\left\{[0 / 90] /+35 /(0)_{2} /-35 / \mathrm{HC}\right\}_{\mathrm{AS}}$

$\mathrm{Lam} 3=\left\{[0 / 90] /+35 /(0)_{3} /-35 / \mathrm{HC}\right\}_{\text {AS }}$

Lam4 $=\left\{[0 / 90] / \pm 45 /+35 /(0)_{3} /-35 / \mathrm{HC}\right\}_{\text {AS }}$

Fig. 4. Effect of ply sequence and number of plies on frequency constraints.

of layers required and its sequence subject to design and manufacture constraints. To start up the study the basic lay up as shown in Table 2 is considered for various regions. Initially there are no $0^{\circ} \mathrm{CFRP}$ ply in the laminate $\left(\{[0 / 90] /+35 /-35 / H C\}_{\mathrm{AS}}\right)$.

The first frequency obtained from FEA is $10.53 \mathrm{~Hz}$. Then, an addition of +35 CFRP ply made the frequency to get boosted. The ply is stepwise laid over the height of the cylinder. Each ply and their effect on frequency with respect to cylinder height is shown in Figure 4. Through this iterative process, the optimum height at which each ply can be dropped can be arrived. It is observed that the longitudinal stiffness of $0^{\circ} \mathrm{CFRP}$ ply is more influential at the root, ox tank region and different interface regions than any other region. This will help to bring down the centre of gravity of cylinder towards root level which is mostly desired for stability.

The ply drop and the effect of bi-directional plies also understood from this study and is found that the bidirectional ply is no need to be laid through out the height of the cylinder. This will also help the cylinder to be relieved at ease from the tool after curing during its fabrication. The final lay up details are shown in Table 3 . The achieved frequency is $12.22 \mathrm{~Hz}$ which fulfills the frequency constraints.

\section{Design validation}

The finite element model of composite sandwich cylinder with the final lay-up with idealized loads is solved for free vibrations. From the results the first lateral and axial mode frequencies are obtained as $12.2 \mathrm{~Hz}$ and $25.57 \mathrm{~Hz}$. Hence, the final lay-up is cleared for frequency constraints. For buckling analysis the additional loads are applied in terms of "g" with $7.5 \mathrm{~g}$ along the axial and $1.25 \mathrm{~g}$ along the lateral direction acting simultaneously. The FE model with the final lay-up with fixed-free boundary conditions is solved for linear buckling analysis using IDEAS. The buckling factors are extracted and it is clear that the first mode buckling factor as 8.1 which is well above 1 . Thus it is clear that the composite sandwich cylinder configuration has met the requirements of buckling. Hence the structure is safe from stability point of view. Using the relations for various local buckling failures the design is also checked for dimpling, wrinkling and shear crimping failures. The results proved that the factor of safety for final lay-up is well above the margins. The ply stresses and ply strains are well below the tested stress levels of prepregs. The Tsai-Wu ply failure index numbers are also below 1. Hence, It is confirmed that the design is safe against strength requirements. 


\section{Conclusions}

The parametric analysis of ply properties on composite cylinder design for satellites is presented in detail starting with basic design equations derived for space requirements. The analytical computation of various stresses with the help of classical laminate theory and load calculations for a satellite has been presented. The ply orientation angle and number of plies have been analysed for arriving optimum design satisfying the static and frequency constraints. The results proved that the higher number of plies are needed closer to the root than the top of the cylinder. The bi-directional prepregs impart additional strength in the interface regions and will give fabrication benefits. The optimum ply properties are good enough to withstand the prescribed loads without any failure. A test cylinder with final lay-up sequence is to be fabricated based on these conclusions and will be tested to validate the structural design of composite sandwich cylinder.

\section{References}

[1] T.P. Sarafin, Spacecraft structures and mechanisms from concept to launch, Microcosm Inc, USA, 1995

[2] H. Baeir, T. Puhlofer, Approaches for further rationalization in mechanical architecture and structural design of satellites, Proceeding of 54th International Astronautical Congress, Bremen, Germany, IAC-03-I 102, 2003

[3] D.R. Mulville, Load analysis of spacecraft and payloads, NASA-STD-5002, 1996
[4] H.R. Goldberg, B.T. Cesul, B.E. Gilchrist, The ICARUS student satellite - A fully autonomous student built small satellite for NASA, Proc. of 16th annual AIAA/USU Conference on Small Satellites, SSC02-I-7, 2002

[5] W.E. Skullney, H.M. Kreitz, M.J. Harold, S.R. Vernon, T.M. Betenbaugh, T.J. Hartka, D.F. Persons, E.D. Schafer, Structural design of the MSX spacecraft, John Hopkins APL Technical Digest 17 (1996) 59-76

[6] W. Sodel, Simplified equations and solutions for the vibration of orthotropic cylindrical shells, J. Sound Vibration 87 (1983) 555-566

[7] C.B. Sharma, M. Darvizeh, A. Darvizeh, Free vibration response of multilayered orthotropic fluid-filled circular cylindrical shells, Composite structures 34 (1996) 349-355

[8] S.W. Tsai, H.A.T. Hahn, Introduction to composite materials, Technomic, USA, 1980

[9] J.R. Vinson, The behavior of structures composed of composite materials, Martinus Nijhoff, USA, 1986

[10] C.D. Reese, C.W. Bert, Simplified design equations for buckling of axially compressed sandwich cylinders with orthotropic facings and core, J. Aircraft 6 (1999) 515-519

[11] S. Vijayakumar, S.K. Basha, R.K. Srinivasan, Design details of CFRP honeycomb sandwich cylinder for I-3000 bus, Structures Group, ISRO, India, 2002

[12] S. Vijayakumar, Parametric based design CFRP honeycomb sandwich cylinder for a spacecraft, Composite Structures 65 (2004) 7-12

[13] T.D. Scharton, Vibration and acoustic testing of spacecraft, J. Sound and Vibration 6 (2002) 1-5

[14] IDEAS User's manual, SDRC, USA, 2000

To access this journal online: www.edpsciences.org/meca 